\title{
Watershed Approach for Sustainable Landscape Development: Technology Transfer from Lab to Land Overview of Rangola - Bhadra Watershed, Gujarat, India
}

\author{
Dr. Sushma Sahai \\ Assistant Professor, Department of Geography, Loreto College, Kolkata, West Bengal, India
}

\begin{abstract}
The Integrated Watershed Management (IWM) approach has been globally accepted as the most viable option for natural resource management, but has not been efficiently implemented because of lack of required framework and/ or technical know-how.

In the current scenario, where emphasis is being placed on making the local-level users participate in the management of natural resources at the watershed level, it is imperative that these local-level organizations be strengthened by providing the integrated watershed management tools which are user-friendly, but have their foundation in scientific knowledge to arrive at the appropriate decisions.

This article is a humble attempt to put forward a scientific approach in the form of Geographical Information Systems (GIS) to handle the IWM strategy through a case study implemented to demonstrate framework for local-level planning, incorporating the sustainability aspects of watershed development. One of the strongest points in favour of IWM is that it provides a platform for integrating the bio-physical and the social. The watershed management involves a large number of guiding principles such as conservation of natural resources, development of natural as well as social resources, in situ soil moisture conservation, sustainable farming system, livelihood support for landless families, democratic decentralization in decision making, equity for resource poor families and empowerment of women.
\end{abstract}

Keywords: Geographical Information Systems, Participatory Rural Appraisal, trickle down approach, Watershed management

\section{Introduction}

Watershed development in India, seen as the panacea, has been directed towards the 'promotion of overall economic development and improvement of the socio-economic conditions of the resource poor sections of people inhabiting the programme areas through natural resource enhancement' (GoI 2001, p.1). The importance lies in the conscious effort to establish interconnectedness between natural resource regeneration and management, livelihood sustenance and participatory institutions.

\section{Integrated Watershed Development Programme}

The programme has been conceived and adopted for holistic development of rain fed farming in recent years. Watershed management is fast becoming a blue print for agricultural development in most parts of the country. The programme aims at conserving soil and moisture as well as to put the lands to use according to their capabilities in order to improve the overall productivity of the catchment.

Watershed management as a strategy has been adopted by Government of India especially in the rain fed regions of semi-arid tropics. These regions are characterized by low and undependable rain, low soil fertility, poor infrastructure development, low literacy and high incidence of migration. Several studies have identified that there is a dire need of a systematic and scientific approach to deal with watershed development. The common guidelines generate a fresh and flexible framework for the next generation watershed development. (Ingle and Kude, 1991).

The ultimate goal of watershed management is to achieve and maintain a balance between resource development, to increase the welfare of the population and resource conservation in order to safeguard resources for the future and to maintain ecologic diversity. As watershed development programme approach is an integrated one, it is necessary to holistically assess and evaluate the long term effects. (Sundara, 1991).

\section{Remote Sensing and Geographical Information Systems (GIS)}

Satellite Remote Sensing plays a vital role in this connection by depicting the status of the watershed before and after the implementation of developmental programmes, indicating the changed scenario. Remote Sensing technology integrated with GIS has emerged has an efficient, time saving, cost effective and indispensable tool for the management of natural resources on a watershed basis. 


\section{Nature of Problem}

Rangola-Bhadra is a typical watershed of the Saurashtra peninsula having problems of excessive soil erosion, soil salinity, overgrazing and abandonment of the traditional water conserving techniques. There is severe shortage of water and droughts occur frequently once in three years.

\section{Objectives}

The fundamental objectives of this study were;

- To examine thematic information by interpreting satellite imageries, Survey of India topographical sheets and analyze the same through GIS software.

$\square$ To increase public understanding and awareness about watersheds, through training.

P Promote better stewardship of private and public lands, and

Transfer of technology to spatially identify the critical zones with respect to above stated problems and sustain watershed management efforts.

\section{Methodology}

The details of this work are based on primary as well as secondary data sources. Primary data was collected from survey of Bhadra village, Botad taluka, Bhavnagar district of Gujarat. Entry point activity is an important work, which helped establish a rapport with the villagers. Villagers are the important stake holders who will be directly benefited from the project. Participatory Rural Appraisal (PRA) was adopted as an important exercise in the study of the micro watershed after great response-confidence building process. To access the impact of any watershed development program a detailed baseline survey has to be conducted. This acts a benchmark for any intervention during and post implementation of any development program. A detailed baseline survey was undertaken which involved household census survey, Bio-physical survey and Village level data collection.

Besides primary data, various publications of Central and State governments were also referred to. The Survey of India topographical sheets, IRS images (LISS II, resolution of 36.25 meters), cadastral maps and census reports provided an integral part of secondary data sources. An extensive literature review spanning the concept of IWM, development of watershed as a unit for planning and case studies of watershed management provided a strong foundation for this study.

Geographical Information System (GIS) was an important decision making tool during the course of this study. ArcView Software was used to assess the physical aspects of the micro watershed.

\section{Location of Study Area}

The micro watershed of Rangola-Bhadra covering an area of 438 hectares extending between $21^{\circ} 42^{\prime} 33.6^{\prime \prime} \mathrm{N}$ to $21^{\circ} 45^{\prime} 43.2^{\prime \prime} \mathrm{N}$ and $71^{0} 37^{\prime} 54.14^{\prime \prime} \mathrm{E}$ to $71^{\circ} 40^{\prime} 46.56^{\prime \prime} \mathrm{E}$ is situated in Botad Taluka of Bhavnagar District. The watershed gets its name from river Rangola and Bhadra the largest village of this region.

Fig.1: Location Map of Bhavnagar district,

Gujarat

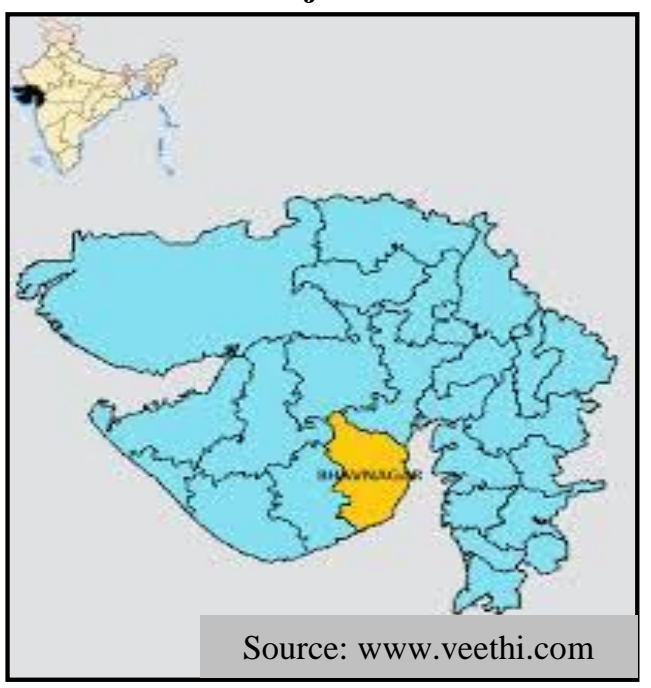

\section{Physical Setting}

Botad taluka in which this watershed is located has a tropical wet and dry climate, with hot, dry summers from midMarch to mid-June, the wet monsoon season from mid-June to October, when the city receives $620 \mathrm{~mm}$ of rain on average. During summer time, the temperature ranges between $24^{\circ} \mathrm{C}$ and $42^{\circ} \mathrm{C}$. In the months of winter, Botad temperature varies between $10^{\circ} \mathrm{C}$ and $22^{\circ} \mathrm{C}$. As Bhavnagar district is a part of Saurashtra region, the major type of soil is Vertisols. These soils are generally developed from parent materials that are rich in alkaline earth cations $(\mathrm{Ca}$ and $\mathrm{Mg})$. 


\section{Strategies for watershed development}

Having identified the watersheds, the next action was to generate detailed information commensurate with the implementation of new technologies and subsequent control and operation of generated resources. A detailed survey was conducted in which Participatory Rural Appraisal (PRA) formed the foundation of this study. This was an indispensable input to focus on creating accountability of the stakeholders towards the program. This has created an emphasis to include all the stakeholder communities and their local and Indigenous Technological Knowledge (ITK) while planning for any activity. Participatory approach provides a new path for planning, implementing, and monitoring and post- withdrawal activities with a complete accountability of the stakeholders. Various PRA techniques like resource mapping, social mapping, and season calendars were used to understand the physical and social orientation of the village in general and watershed in specific.

\section{Hindrances in the Watershed Development Programme}

There are many natural and man made situations, which affect the normal process of development. Some of them were as follows;

* Lack of awareness due to illiteracy

* Lack of participation and local politics

* Lack of technical knowledge and suitable human capacity

* Resistance from local villagers

* Lack of funds

* Lack of authentic information and statistics

\section{Findings}

Field visits suggest that overexploitation of groundwater, encroachment by people for agriculture and consequent erosion has reduced much of the area to a highly degraded state. A physical assessment of the Rangola-Bandra watershed has been carried out with the help of GIS.

In order to identify the problem areas within the watershed it was essential to assess the status of soil, slope, groundwater and the land use pattern. The spatial variations of each of these factors would have an impact not only on the physical landscape but also have repercussions on the economic base of the watershed.

The Rangola- Bhadra Watershed was dominated with fine loamy and loamy skeletal soils. Fig.2 illustrates the soil map which has been computed on the basis of study of Satellite imageries (Geocoded standard False Colour Coded) on 1: 50,000 scale and topographical sheets. Since soils are composed of mineral and organic constituents with varying amounts of soil moisture they have different reflecting capacity. It is the signature or the spectral reflectance of various soils that enables their identification and assess its level of fertility.

Fig.2

Fig. 3

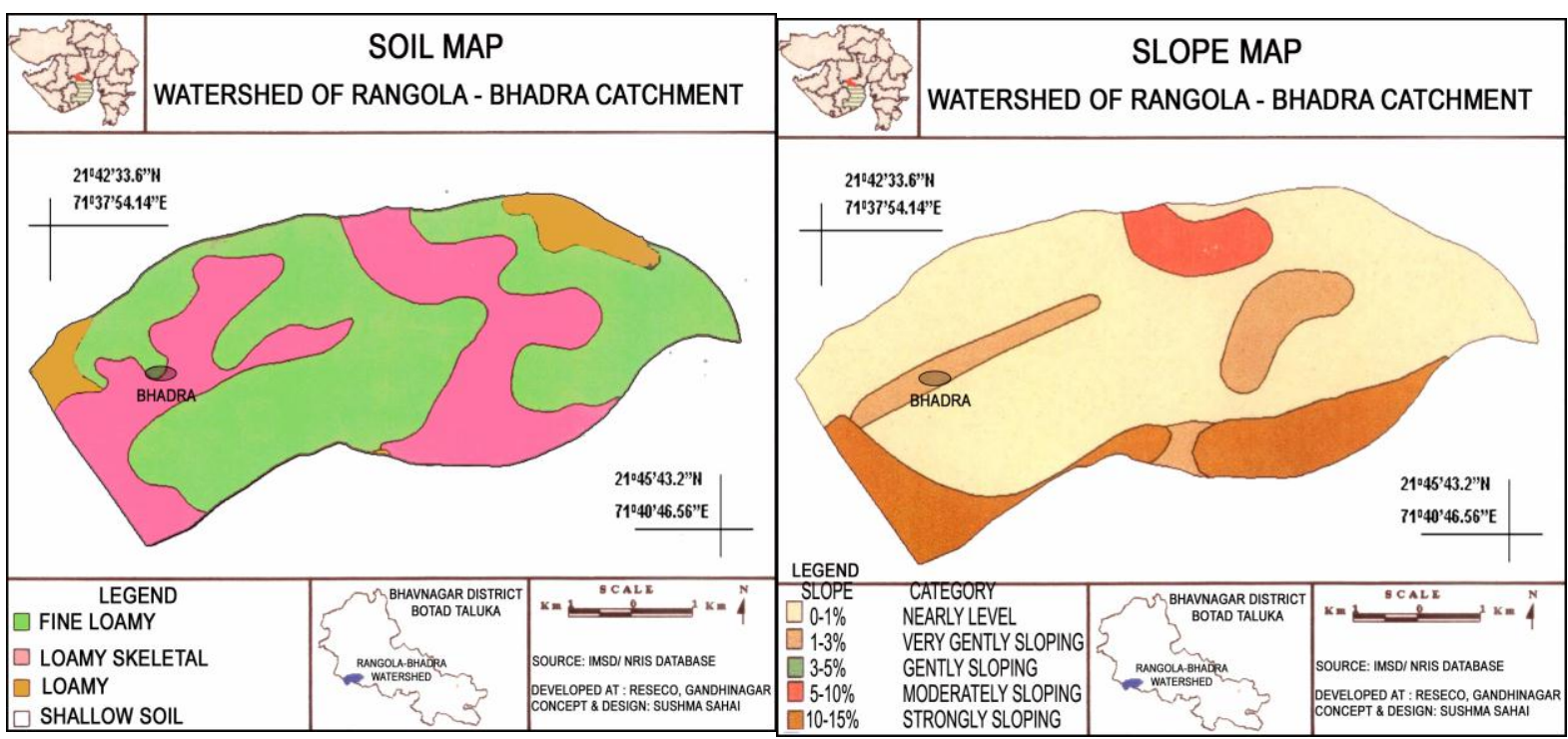

Slope is an important parameter required for:

i) Characterization of the watershed in terms of soil loss, run off potential etc.,

ii) Revaluation of the functioning of the terrain, and 
iii) Suggestion of conservation measures.

Information on elevation was acquired from Survey of India topographical sheets. Digital GIS techniques have been employed to generate the slope map which shows four main categories. As seen in Fig.3 excepting the southern fringes of the watershed which has a steep gradient of $10-15 \%$, the maximum area has a nearly level slope ranging between $0-1 \%$.

Groundwater is a renewable resource that has significant effect on agricultural production in India. De jure property rights in groundwater are not clearly defined but de facto it is accessible to all those who own the overlying land. Lack of well defined property rights, its indivisibility and insurmountable difficulties in assessing and monitoring its stocks as well as flows makes groundwater unmanageable and prone to over exploitation.

Groundwater irrigation accounts for more than fifty percent of the net irrigated area in India. It contributes to more than half of the country's total agricultural production from irrigated areas. It is thus essential to assess and forecast future trends of water levels in response to the adoption of modern techniques of groundwater extraction.

Fig.4

Fig.5

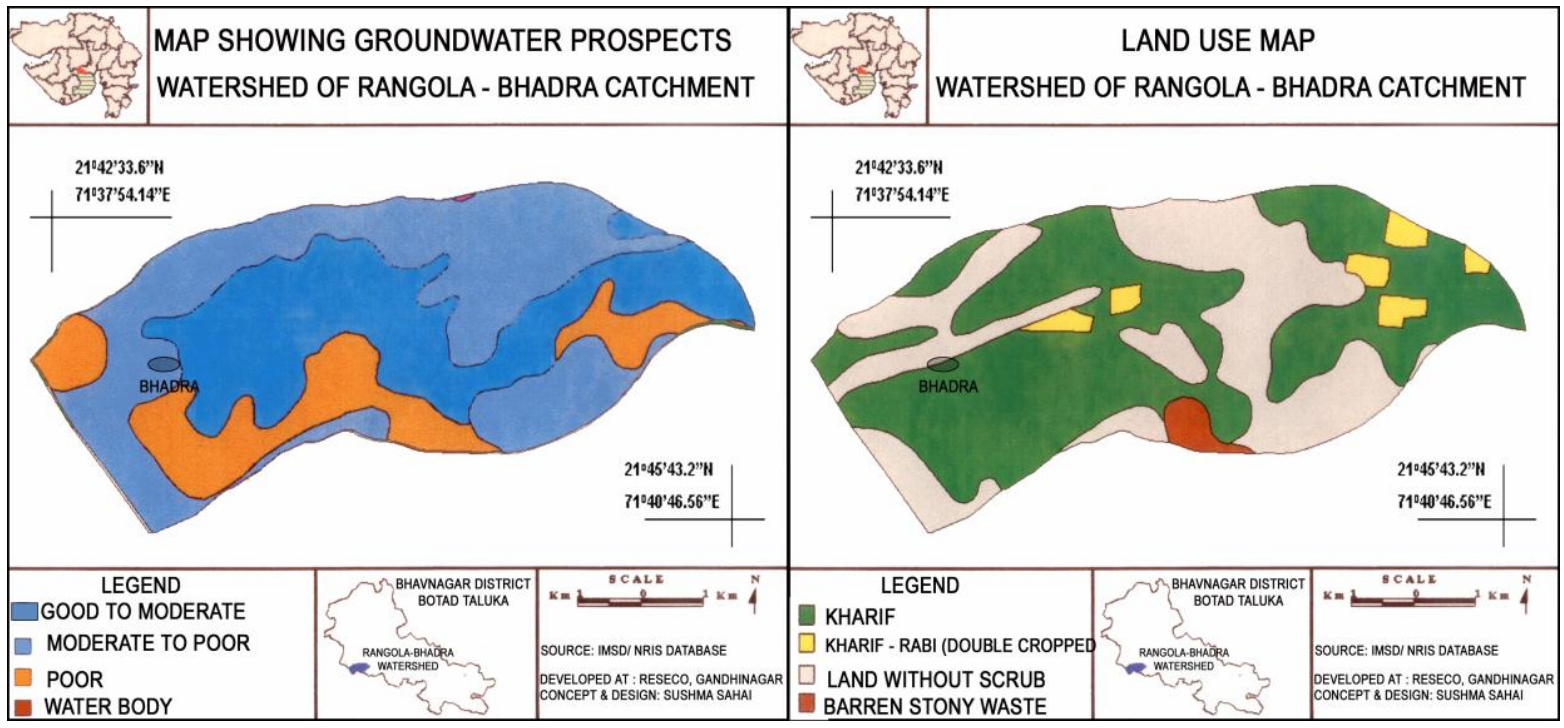

The groundwater prospects of the study area is illustrated in Fig.4, which indicates that except certain tracts in the southern and north-eastern part the groundwater prospects range from good to moderate. This area coincides with the kharif and kharif- rabi double cropped regions shown in Fig.5.The land use map indicates that the southern parts of the watershed are comprising of land without scrub and barren stony waste which coincides with strongly sloping (10-15\%) covered with skeletal soils having poor groundwater prospects.

\section{Geographical Information Systems - A Decision Making Tool}

GIS is one of the most effective tools for processing, integrating and interpreting multi-data sets. The technique allows geometrically superimposing various kinds of data sets like soil, sloping, landing use, etc.Through such superimposition of data, easy interpretation that may otherwise be difficult and time consuming can be obtained. (P.Nag, 1992). As this watershed is located in the agro-climatic zone of semi-arid Saurashtra, it is essential to identify potential soil erosion risk zones.

GIS module is used for analysis, performing a weighted-sum analysis of multiple output. This gives precise distribution of various features and ideas about the capabilities of GIS technology for data integration and analysis.

The vulnerability of an area to soil erosion depends on the type of soil, degree of slope, amount of rainfall and nature of land use. The Index Programme of ERDAS Software has been used to delineate four areas with varying vulnerability to soil erosion. The extremely vulnerable areas shown in Fig.6 comprise steeply sloping lands with thin soil cover and are devoid of vegetation. It is the overlaying and integrating capability of GIS that possess an edge over the conventional means in watershed development. This exercise helped in identifying priority zones, where measures had to be taken immediately to regenerate and revive them. 
Fig.6

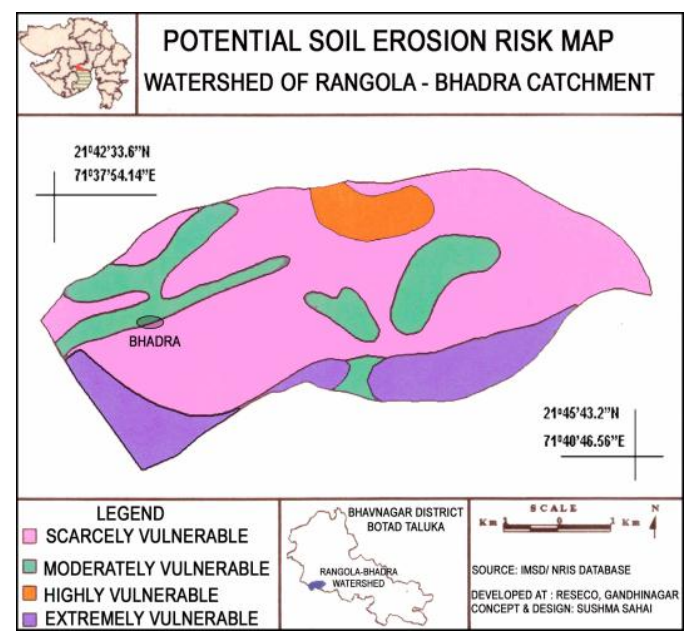

One of the best means to locally enhance the soil moisture level would be to harvest water using traditional methods like rainwater harvesting and constructing check dams. This would enable to capture raindrops and store water effectively within the soil profile and within the vegetal cover. This "Green water" technology can be extended throughout the arid, semi-arid and drought-prone zones of India. Few people have made Rain roof water Harvesting Structure by indigenous design which has good quality but quantity is not sufficient for the whole the year.

The above example is a demonstration of latest tools to derive the appropriate information through analysis and modelling to help in the local-level planning for IWM. This also has the strength of making these decisions highly understandable to all the stakeholders and thereby enhance the local-level participation.

\section{Measures for Watershed Development}

口 Soil and Moisture Conservation

- Agro-Forestry - Local accasia (babool), khejdi, rosewood (sheesham) and ardoo can be planted on field boundaries.

- Horticulture - Commercial crops like myrobalan (anvla), grapes, lemon, guava, palm, papaya etc. would give a higher yield per hectare compare to other crops.

- Pasture development- To decrease the pressure of uncontrolled grazing, improved varieties of grass seeds can be sown to develop pastures. Grasses fuel and fodder tree species like Israeli acacia (babool),Jhad beri (Plum) and Kumat etc.,can be planted.

- Traditional Means of water harvesting

- Vermiculture should be adopted to reduce the dependence on chemical fertilizers

Capacity building and training with special emphasis to empowerment of women

\section{Present and Future Directions}

The experiences of this study are varied, and they include a number of successful as well as less effective interventions. The above mentioned measures to a great extent transformed the physical, social and economic landscapes. Soil and water conservation recharged the groundwater table and consequently metamorphosed the land use of this area. The fallow tracts were judiciously used for cultivation of fodder crops or pits for vermicomposting. This proved as a twin edged sword which not only increased the production but also brought about a significant increase in the income of the stakeholders. This had a ripple effect in the form of reduction in out-migration of the male workforce, thereby restoring the original societal structure. The Quality of life improved manifold primarily due to the empowerment of the women of Bhadra village. Subsequent review of this project reflected significant improvement in the health and general well-being of the women of this area. One of the integral part of IWM was the value-addition of the products like extraction of oil from white sesame and pickle from lemon. These were marketed to Bhavnagar, district headquarters and the capital city of Ahmedabad which ensured a steady livelihood for the villagers.

\section{Conclusion}

It is evident from the study that participatory paradigms of watershed concept are highly dynamic, situation or resource specific and still in evolutionary process. Community participation and technical knowledge are the two pillars of watershed development and the coordination between them is necessary. Ensuring equitable distribution of benefits, goods and services from watershed development particularly to those who have no rights to land and water is a formidable task. The development of common lands, improvements in the vegetative cover and above all rejuvenating the age-old practices of water conservation would lay a strong foundation for the Rangola - Bhadra watershed to ensure sustainable livelihoods. The trickle down approach in terms of technologies, participatory institutions, access to infrastructure and market in a long-term framework seems to be the basis of success of watershed programme. The watershed should adopt a Public - Private Partnership (PPP) model which would help achieve the objectives and create a win - win situation for all 
stakeholders. These partnerships will strengthen market linkages and generate employment opportunities for the inhabitants.

\section{References:}

[1]. Government of India, Guidelines for Watershed Development. New Delhi: Ministry for Rural Development, 2001, 1

[2]. P.O.Ingle, N.R.Kude, 'Comprehensive Watershed Development Programme: An Evaluation', Yojana, 1-15 March, 1991, 17-19.

[3]. R.M.Sundara, Remote Sensing and Geographical Information Systems for Natural Resource Management, Asian Development Bank, 1991.

[4]. P.Nag, Thematic Cartography and Remote Sensing, Concept Publishing Company, India, 1992. 